\title{
Appropriateness of Burning Rate measuring Technique with The Measuring Conditions and Requested Data
}

\author{
Ahmed Maraden *,1, Petr Stojan**, Robert Matyáš *, Ondrej Vodochodsky * \\ * Institute of Energetic Materials, Faculty of Chemical Technology, University of Pardubice, \\ CZECH REPUBLIC.
}

** OZM Research, s.r.o., Blížňovice 32, 53862 Hrochův Týnec, CZECH REPUBLIC.

\begin{abstract}
Burning rate data are usually obtained in several ways. Small-scale ballistic evaluation motors, constant volume vessels, standard strand burners and full-scale motors with good instrumentation are the most common methods for measuring the ballistic properties of solid propellant. The objective of this work is to describe the facilities developed by every measuring technique and validate the new developed SV-2 for strand burning measurements at low and high pressures. Modifications have been made to use the SV-2 closed bomb as a Crawford bomb. The sample holder and the closing tip were totally changed to enable burn rate measurements at the form of strand burn measuring. The burning rate of the different commercial extruded double base has been measured using the modified SV-2 strand burning and compared with the burning rate resulted from subscale rocket motors. Results showed that the burning rates generated from both methods are comparable and close to each other. One firing from the subscale motor or strand burning is equal to one point on the $P-u$ curve. Effect of initial grain temperature on the combustion process has been investigated using SV2 closed vessel method compared to the subscale rocket motors method. Changes in the ignition process have been reported through the variations in the durations for the different ignition zones. The burning criteria have been studied through the $P-t$ curves and the actual burning time. The burning parameters, pressure exponent $n$ and temperature coefficient $a$, have been calculated. Results showed that raising the initial grain temperature increases the ignitability, the burning rate, and operating pressure. The suitability of the burning rate measuring technique has been discussed. The subscale rocket motors can be considered the closest method to simulate the reality in spite it requires more money, efforts, and time consuming. Strand burning measurements are favorable to measure the burning rates at lower operating pressures (2-10 MPa) while it is not suitable for investigating the initial grain temperature effect on the combustion process. SV-2 closed vessel can be considered a more convenient method to measure the burning rate from economical point of view.
\end{abstract}

Keywords: Burning rate; Strand burning; Subscale rocket motor; SV-2 closed vessel; Double base propellant.

\section{Introduction}

During development of a new or modified solid propellant, it is extensively tested. One of the most important design criteria of rockets running with solid propellants is the burning rate and the burning rate dependency on the operating pressure [Kirk and Jolley (1977)]. For this

\footnotetext{
${ }^{1}$ Coressponding Author : phone: +420775044238, E-mail: st50389@ student.upce.cz
} 
reason, the burning rate of the propellant which will be used in rocket motors must be tested. This includes testing of the burn rate (in several different ways) under different conditions [Young (1960), Hessler and Glick (1997), Ulas et al. (2006)]. Burning rate data are usually obtained in several ways [Fry (1995, 2001a), Yilmaz (2008)]. Small-scale ballistic evaluation motors, constant volume vessels, standard strand burners and full-scale motors with good instrumentation are the most common methods for measuring the ballistic properties of solid propellant [Garima (2015)]. In general the burning rates obtained by different techniques are not the same; even using identical specimens and the same technique at different facilities, the measured burning rates are different due to a variety of details not fully controllable or controlled [Hermance (1961)]. The relationship between measured burning rates is determined empirically for each propellant category and grain configuration [Hessler and Glick (1999), Fry (1998, 2001b, 2001c)]. Tests with the small motors provide better correlation with full-scale motor burning rates, but are considerably more time- and moneyconsuming than tests in closed vessel and strand burners [Fry (2001d), Deluca et al. (2002)]. A strand burner is an apparatus that provides burning rate measurements of a solid rocket propellant at elevated pressure [Nelson (1977), Pietrobon (2003)]. This technique was developed by Crawford and co-workers [Crawford et al. (1947)] in 1947 and later modified by Grune [Grune et al. (1977)]. It was used to evaluate new propellant formulations and ensuring quality control for a large propellant production, due to its low cost, simplicity and ability to produce good results in a short time period compared to sub-scale and full scale motors [Collins (1947), Phung and Hardt (1968), Rodolphe et al. (2005)].

The initial temperature of solid propellants is one of the main factors which directly affects the performance of the rocket motor [Degirmenci (2015), Yaman et al. (2014), Glick (1967), Xiong et al. (2011), Blan and David (1970), Ewing and Osborn (1971)]. In rocket motors, a change of $25-35 \%$ in combustion chamber pressure and $20-30 \%$ in combustion duration can occur [Agrawal (2010), Yilmaz et al. (2008), Shekhar and Himanshu (2009), Daenas (1993)]. Temperature affects the rate of chemical reactions and thus the initial temperature of the propellant grain influences burning rate [Kubota (2002), Kosanke et al. (2004), Atwood (1999)]. If a particular propellant shows significant sensitivity to initial grain temperature, operation at temperature extremes will affect the time-thrust profile of the motor.

\section{Experimental work}

\subsection{Propellants and grain properties}

Commercial extruded double base propellant compositions manufactured and provided by Explosia Company have been used for evaluating the methods for solid propellant burning rate measurement. Table 1. lists the used extruded double base compositions. Subscale rocket motor testing was performed in Explosia test stand area using their facilities and obeying their standard testing rules. Modified SV-2 for strand burning measurements adjusted by OZM Research Company and located in the Institute of Energetic Materials, University of Pardubice was tested for burning rate measuring. Figures 1. and 2. illustrate the sample configuration and the sample holding for both subscale rocket motor and the modifications done on the SV-2 lid to act as a Crawford Bomb respectively. 
Table 1: Composition of the double base propellant (\% by wt.) used

\begin{tabular}{cccc}
\hline Composition $(\%)$ & ROP & $\begin{array}{c}\text { Propellant } \\
\text { GRAD }\end{array}$ & 1331 \\
\hline Nitrocellulose & 55.0 & 57.5 & 59.77 \\
$(\%)$ nitrogen content & $\left(12 \% \mathrm{~N}_{2}\right)$ & $\left(12.01 \% \mathrm{~N}_{2}\right)$ & $\left(12.05 \% \mathrm{~N}_{2}\right)$ \\
Nitroglycerine & 28.5 & 26.5 & 26.01 \\
2,4-Dinitrotoluene & 8.5 & 8.6 & -- \\
Tri ethylene glycol di nitrate & -- & -- & 8.21 \\
Centralite I & 2.5 & 2.9 & 3.13 \\
PbO & 1.2 & 1.4 & -- \\
CaCO & 2.1 & -- \\
Zinc stearate & 1.6 & 0.1 & -- \\
Organo-metal modifier & 1.1 & -- & 2.88 \\
Carbon black & -- & -- & -- \\
Transformer oil & 0.7 & 0.9 & -- \\
\hline
\end{tabular}

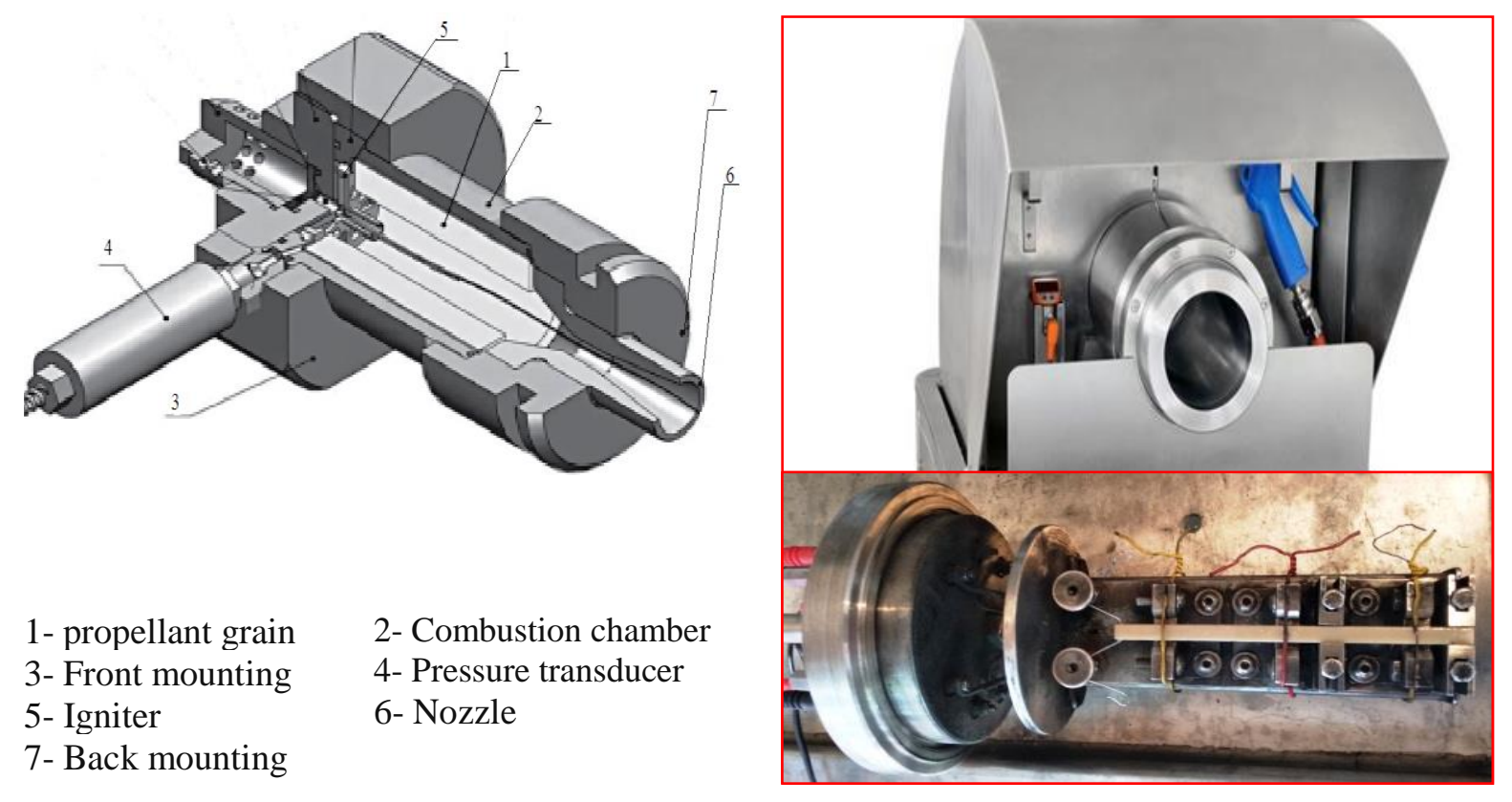

Figure 1: Subscale test rocket motor.

Figure 2: Modified SV-2 vessel for strand burning.

\subsection{Burning rate measurement}

\subsubsection{Modified SV-2 for strand burning}

Strands of propellant having square cross section $(5.25 * 6.24 \mathrm{~mm})$ and length $123.2 \mathrm{~mm}$ are employed. Strands are coated with three inhibition layers to prevent side burning and the inhibited strands hanged in air for curing. The sample is left for about thirty minutes after applying each layer for complete drying and adhering of the layer to the propellant surface. Three small holes are drilled along the sample fitted to the three thermocouples at sample holder. Accurately measured distances $43.1 \mathrm{~mm}$ is the distance between each two subsequent 
holes. The samples are then stored in the tempering box for at least 24 hours to maintain their temperature at $20^{\circ} \mathrm{C}$. Eight sets, each set consists of two strands, have been prepared for each composition. It took maximum 2-3 minutes between samples getting out from the tempering box till the firing of the sample. Tests were performed at $20{ }^{\circ} \mathrm{C}$. The sample is installed to the particular grooves and standing horizontally, see figure 2 . The vessel was pressurized to the required operating pressure using nitrogen gas.

The strand is ignited at one side by a hot wire which is located $17.5 \mathrm{~mm}$ from the first thermocouple. As the propellant start to burn, the pressure begins to build up by the combustion gaseous product. A controlling pressure valve is automatically working to keep the operating pressure within around $\pm 1-4 \%$ range of the desired pressure. The automated pressure regulator is opened periodically to lose pressure accumulated by propellant burning keeping the vessel pressurized to the desired operating pressure. The time taken for burning to pass from the first to the third thermocouple through the second thermocouple is accurately measured. From the distance between each two thermocouples and the time taken for propellant strand to burn, the burning rate is being calculated. The burning surface should remain planar and normal to the strand axis. The propellants burning rate has been measured at 2.5, 5, 7.5, 10, 12.5, 15, 17.5, and $20 \mathrm{MPa}$. Two measurements are taken at each pressure.

\subsubsection{Subscale rocket motors}

Burning characterization measurements were performed in the premises of Explosia a.s. Tests were performed at ambient temperature of $20{ }^{\circ} \mathrm{C}$. In total, 7-8 sets are fired for each propellant composition each set consists of two rocket motor trials for each desired operating pressure to cover the pressure range from 5-20 MPa with 7-8 points curve. The sets are different in the ratio between the initial burning surfaces of the propellant grain and the nozzle throat area. Cartridge-loaded grain configuration had been used for this purpose. Tubular grains with internal and external ignitable burning surfaces have been used for burning rate assessment. Other surfaces were inhibited by applying two layers of the glue inhibitor and adhering of a circular rubber cover. Tube length about $123 \mathrm{~mm}$, outer diameter $\approx 24 \mathrm{~mm}$, inner diameter $\approx 13 \mathrm{~mm}$, and web burning thickness $\approx 2.75 \mathrm{~mm}$. The grain configuration produces a neutral burning behavior and is used for single point firings of the burning rate/pressure characteristic, $r_{b}(\mathrm{p})$, of a propellant. Grain length / diameter ratio $>2$ to minimize erosive burning, short burning duration (2-10 s) to minimize heat losses and nozzle erosion, small grain web thickness to minimize thermal shrinkage. By varying the nozzle throat, the operating pressure inside the combustion chamber is changed and the burning rate of the propellant is determined over the desired pressure range. Different nozzle throat diameters have been used. The thickness of the Al membranes used was $0.1 \mathrm{~mm}$. To ensure proper ignition, the required amount of black powder needed for ignition and achieving the desired operating pressure has been calculated for each nozzle and for each composition.

\subsection{Effect of temperature on burning process}

\subsubsection{SV-2 closed vessel}

Extruded double base propellants ROP and GRAD given in table 1, supplied by Explosia company have been used for burning rate measurement at different initial grain temperatures 
of $-20{ }^{\circ} \mathrm{C},+20{ }^{\circ} \mathrm{C},+40{ }^{\circ} \mathrm{C}$, and $+60{ }^{\circ} \mathrm{C}$. Samples dimensions and weights have been measured and the web burning thickness is accuratly measured. Tube shape samples have been used with internal and external burning surfaces and inhibited circular ends. Tube length about $123 \mathrm{~mm}$, outer diameter $\approx 24 \mathrm{~mm}$, inner diameter $\approx 13 \mathrm{~mm}$, and web burning thickness $\approx 2.75 \mathrm{~mm}$. Samples are prepared by inhibiting the restricted surfaces by applying three inhibitor layers and held to the sample holder. Samples for cooling are cased with a thin plastic casing to prevent the action of humidity when getting the samples out from the refrigerator. The samples were heated or cooled using special heating and cooling equipments for 24 hours before firing to achieve the desired grain temperate. The heating and cooling devices worked in the ranges of 10 to $65{ }^{\circ} \mathrm{C}$ and -40 to $0{ }^{\circ} \mathrm{C}$, respectively. For testing, the samples were taken from the tempering devices and immediately constructed to the closed vessel, time interval maximum one minute, in order to minimize the heat losses. Reproducibility of results was confirmed by two shots at each required temperature. Black powder $(0.5 \mathrm{~g})$ was used as the igniter and $5 \mathrm{~g}$ of black powder was used as a booster to ensure the proper initiation for the samples by spreading the igniter flame all over the sample burning surfaces. The pressure profiles were reported and an advanced mathematical procedure produced by OZM Research Company based on the most modern computational and ballistic procedures was applied to calculate the burning rate dependency on the pressure.

\subsubsection{Subscale rocket motor}

Burning characterization measurements were performed in the premises of Explosia a.s. The ambient temperature at the test stand was $20^{\circ} \mathrm{C}$. Burning rate has be measured for initial grain temperatures of $-60{ }^{\circ} \mathrm{C},-20{ }^{\circ} \mathrm{C},+20{ }^{\circ} \mathrm{C}$, and $+60{ }^{\circ} \mathrm{C}$. Tubular samples identical to that used for the closed vessel have been used for the subscale rocket motors. The assembled sets (propellant in subscale rocket motor) were heated or cooled using special heating and cooling equipments for 24 hours before firing to achieve the desired grain temperate. The sets were taken out of the oven or refrigerators just prior to the measurement to minimize the effect of ambient temperature on the subscale rocket motor temperature. The handling time between taking the motor out of the oven / freezer and shooting was maximum 1 minute. Various nozzles and membranes have been used to obtain different operating pressures. For each temperature, five different nozzle throat diameters of about $7.8 \mathrm{~mm}, 7.3 \mathrm{~mm}, 6.9 \mathrm{~mm}, 6.6 \mathrm{~mm}$ and $6.3 \mathrm{~mm}$ were used. The thickness of the membranes used was between 0.1 to $1.0 \mathrm{~mm}$. In total, 20 sets were fired for each propellant composition; for each temperature, 5 rocket motors differing in the ratio between the initial burning surfaces of the propellant grain and the nozzle throat area.

\section{Results and discussions}

\subsection{Burning rate measurements}

\subsubsection{Modified SV-2 for strand burning}

As the chamber lid acts as the sample holder, it takes some time between shots for preparing the new firing for constructing the sample to the thermocouples and connecting the ignition wires. Figure 3 shows the eight points curve for the calculated burning rate from the modified SV-2 for strand burning measurements. The time interval of combustion between the thermocouples is measured at the same levels of the electrical signal beginning from the 
thermocouples. In this way, we have three measured time values from each strand, the time between first and second thermocouples, the time between second and third thermocouples, and the total dependent time between the first and the third thermocouples. The propellant is ignited from one side by means of a hot wire and the burning rate is calculated from the distance between the thermocouples and the elapsed burning time between the thermocouples. For the pressure ranging from 5-20 MPa, about 42 shots for strand burning have been performed.

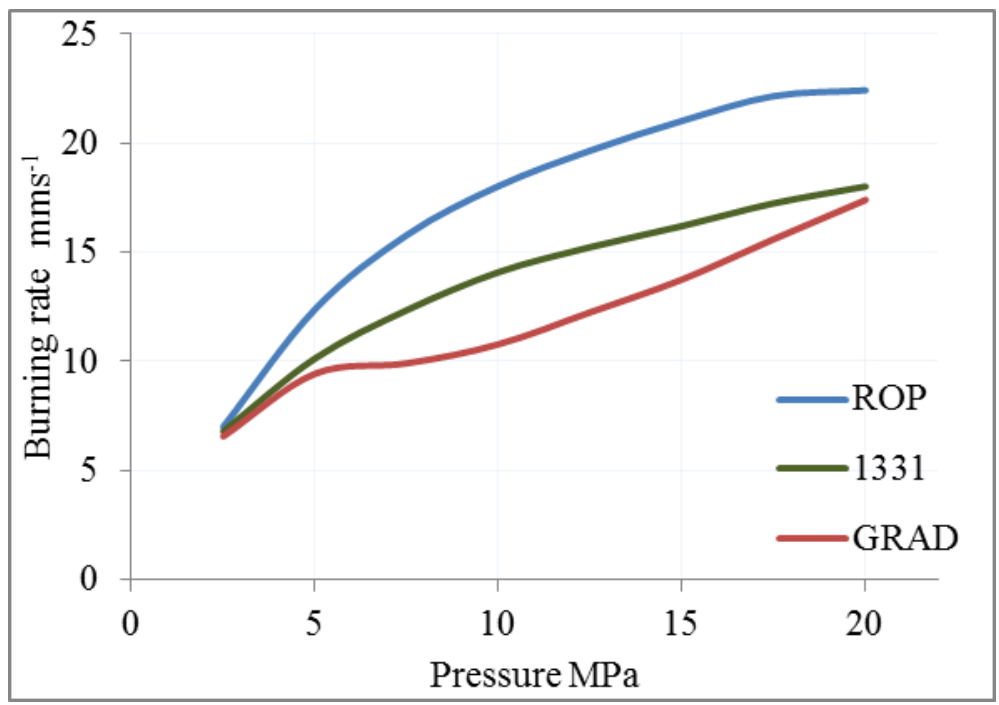

Figure 3: Burning rate measured by modified SV-2 for strand burning

\subsubsection{Subscale rocket motors}

At least 16 shots have been fired for each composition. Some shots have been repeated three times due to some technical problems or combustion instabilities at lower pressures. Figure 4 represents the $P$ - $t$ curves obtained from the fired subscale rocket motors for ROP, GRAD, and 1331 while figure 5 shows the burning rate for the compositions calculated from subscale motors data.
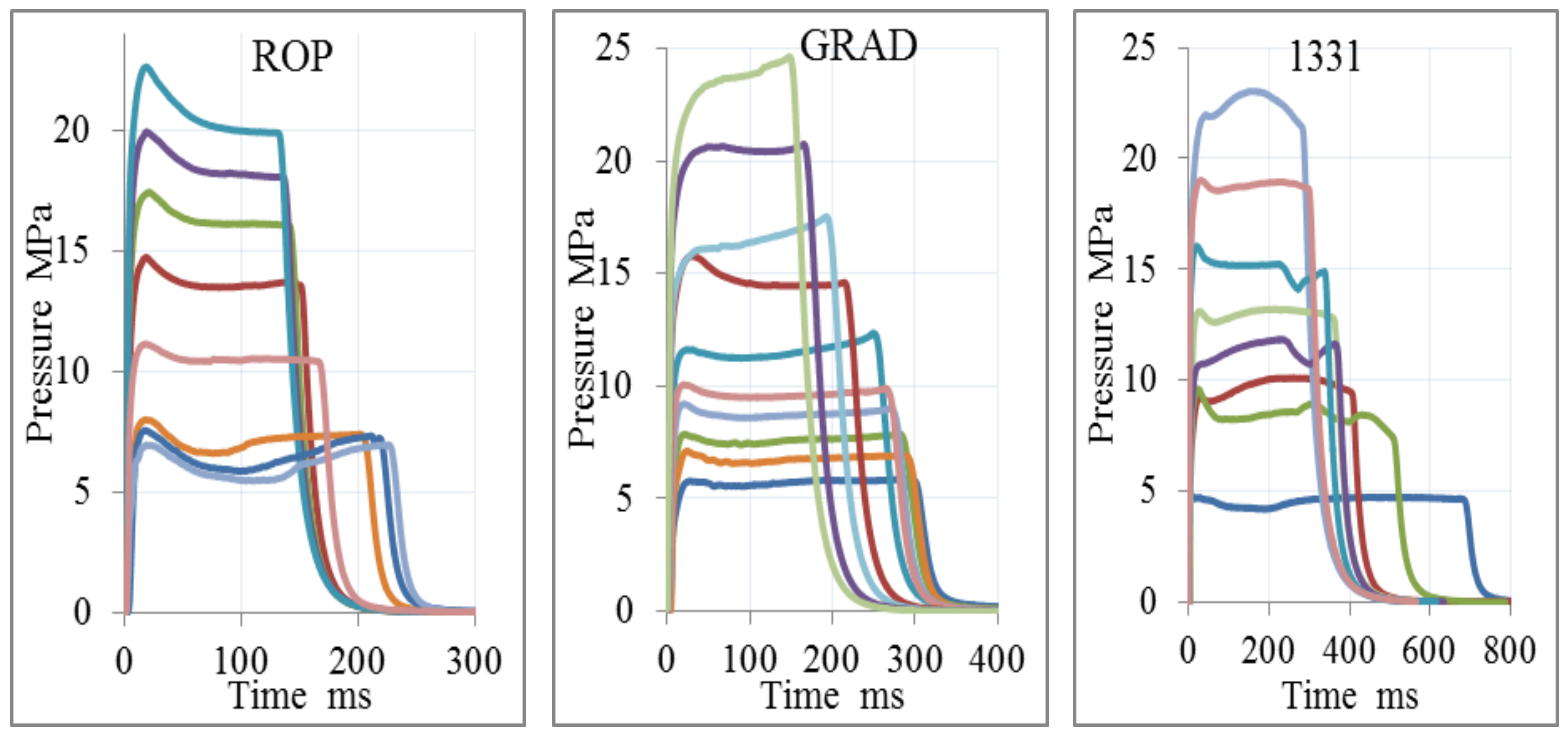

Figure 4: $P$ - $t$ curves for the commercial propellants using subscale rocket motors. 
The resultant $P$ - $t$ curve can be used for calculating the ballistic properties if the difference between the maximum and the minimum pressures does not exceed more than $10 \%$. Igniter has an important role in achieving the operating pressure and performing a uniform burning for the propellant grain. All the given $P$ - $t$ curves have the proper initiation which must be considered for calculations. Other $P$ - $t$ curves which are not uniform or have combustion instabilities are omitted and have not been considered. For ROP composition, firing at operating pressure $5 \mathrm{MPa}$ was unsuccessful accompanied with a lot of combustion instabilities while firing at operating pressure about $7 \mathrm{MPa}$ was on the borders to obtain data which are good for calculating the burning rate. The chamber pressure increased with decreasing the nozzle throat diameter for constant grain configurations. Subscale rocket motors are not favorable for burning rate measurements at lower operating pressures $(<5$ $\mathrm{MPa})$ due to combustion instabilities arises inside the combustion chamber which greatly affects the $P$ - $t$ data curve leads to miscalculating the burning rates.

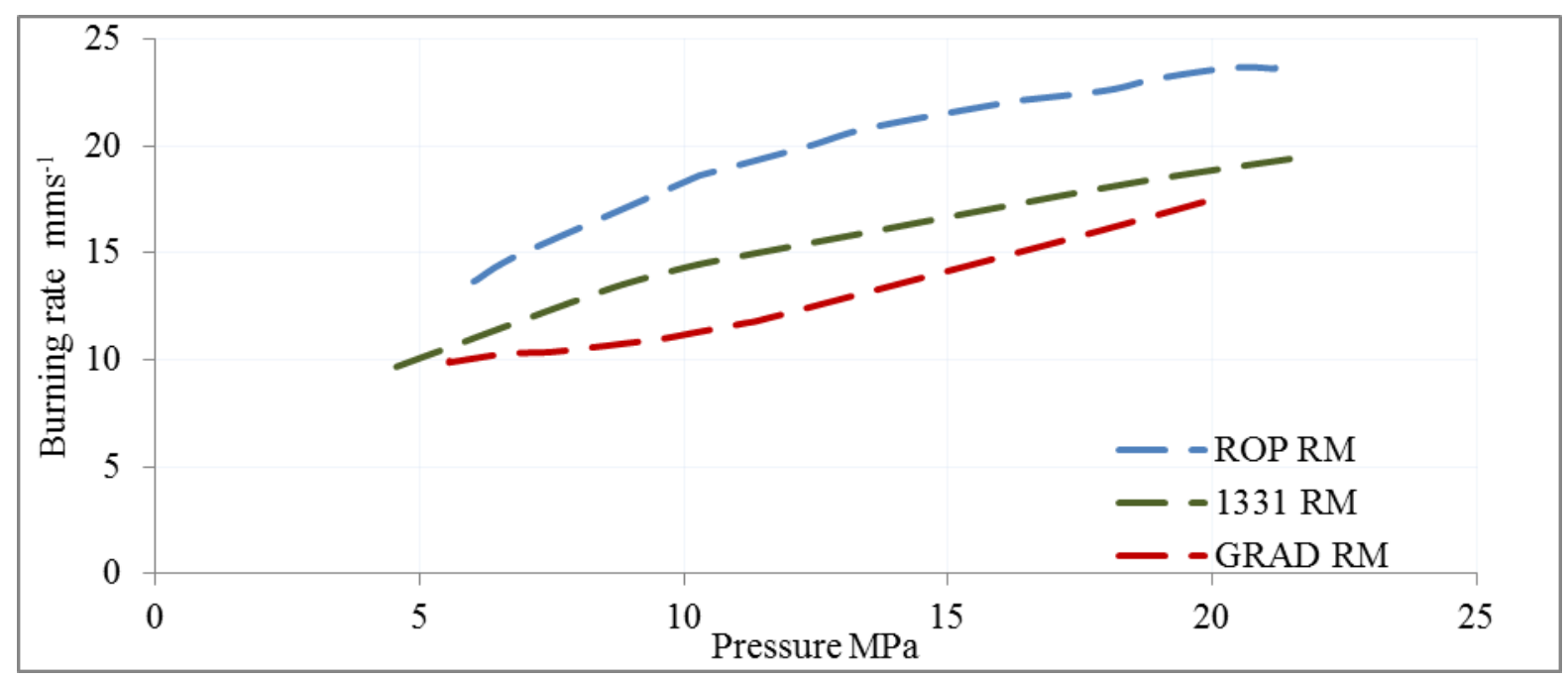

Figure 5: Burning rate for ROP, GRAD, and 1331 by subscale rocket motors.

Figure 6 compares the burning rate data generated from the different measuring methods for different extruded double base formulations. Although all the measurements obtained from the subscale rocket motors are slightly higher than obtained from the modified SV-2 strand burning, The burning rates generated from both methods are comparable and close to each other. The lower burning rate measured by the strand burning may be caused by the effect of cold nitrogen gas pressurized from high pressure storage bomb to relatively lower pressure measuring bomb. The sample temperature may be affected by the low temperature nitrogen gas which consequently affected the measured burning rates. Calculated ballistic parameters $a$ and $n$ generated from data sources are tabulated in table 2. One firing in the subscale motor or strand burning is equal to one point on the $P-u$ curve. Strand burning is more suitable for testing at lower operating pressures (2-10 MPa). 


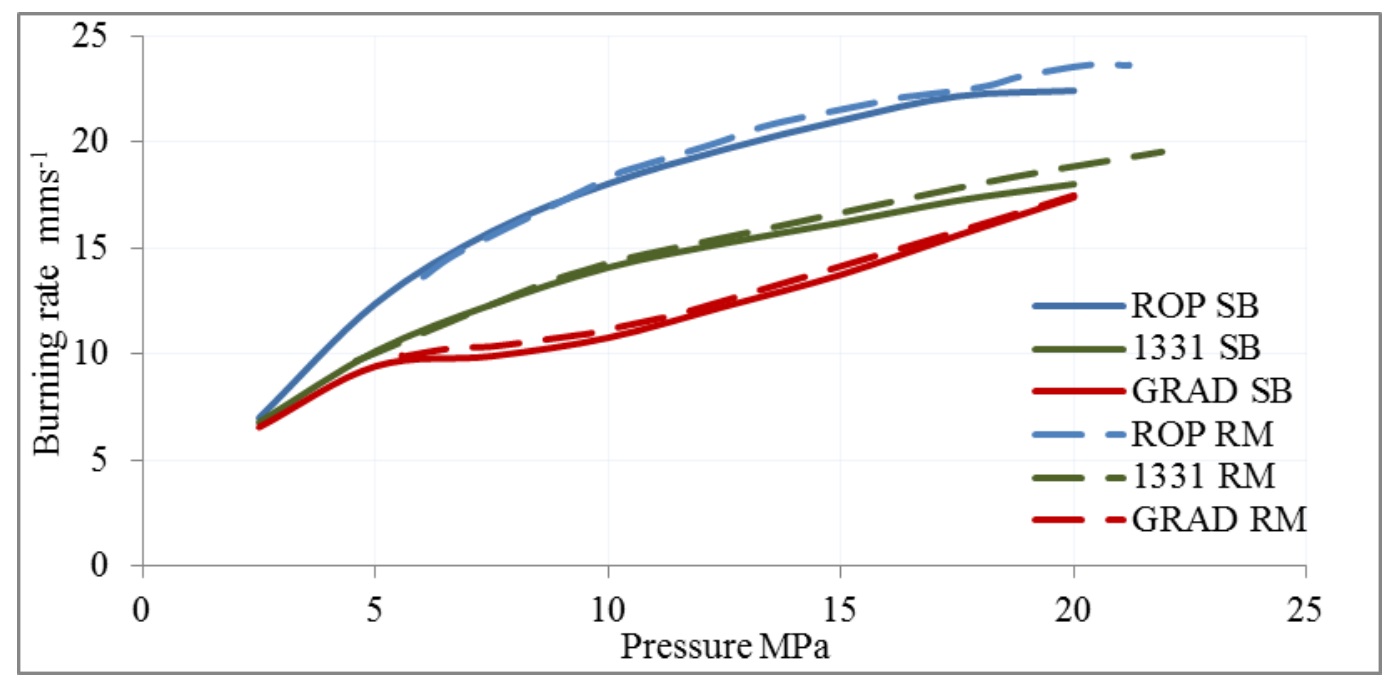

Figure 6: Comparing the burning rate measured by both methods for the commercial extruded double base compositions

Table 2: Calculated $a$ and $n$ parameters.

\begin{tabular}{c|c|c|c|c}
\hline & \multicolumn{2}{|c|}{ Pressure Exponent $n$} & \multicolumn{2}{c}{ Temperature Coeff. $a$} \\
\cline { 2 - 5 } & RM & ST & RM & ST \\
\hline ROP & 0.45 & 0.46 & 5.81 & 5.65 \\
\hline P (MPa) 5 : 20 & & & & \\
PRAD & & 0.19 & 6.72 & 6.35 \\
P (MPa) 5 : 10 & 0.18 & 0.69 & 2.23 & 1.99 \\
\hline 1331 $: 20$ & 0.65 & 0.69 & 4.28 \\
\hline
\end{tabular}

\subsection{Effect of temperature on the burning process}

\subsubsection{SV-2 closed vessel}

The dependency of the burning phenomena on the initial grain temperature was carried out by two shots for each composition at each desired temperature. The pressure profile is reported and the burning rate was calculated. The time needed to reach a certain value of pressure and the total burning time is shortened by increasing the initial grain temperature. As the initial temperature of the propellant grain increase, the time needed for the ignition is decreased while the rate of pressure increase, $\frac{\Delta \mathrm{P}}{\Delta \mathrm{t}}$, and the end burning pressure were increased. It is evidence that the burning rate has been increased by increasing the initial grain temperature. Figures 7 and 8 show the SV-2 ballistic evaluation for the propellants while table 3 lists the measured and calculated data from the SV-2 firing test for the two compositions ROP and GRAD over the whole pressure range. For ROP composition, the temperature coefficient, $a$, was increased with increasing the initial grain temperature while the pressure exponent, $n$, is slightly decreased. GRAD composition introduced a plateau burning at pressure range 3 to $10 \mathrm{MPa}$. At this pressure range, the pressure exponent increased with temperature and the temperature coefficient slightly decreased. 


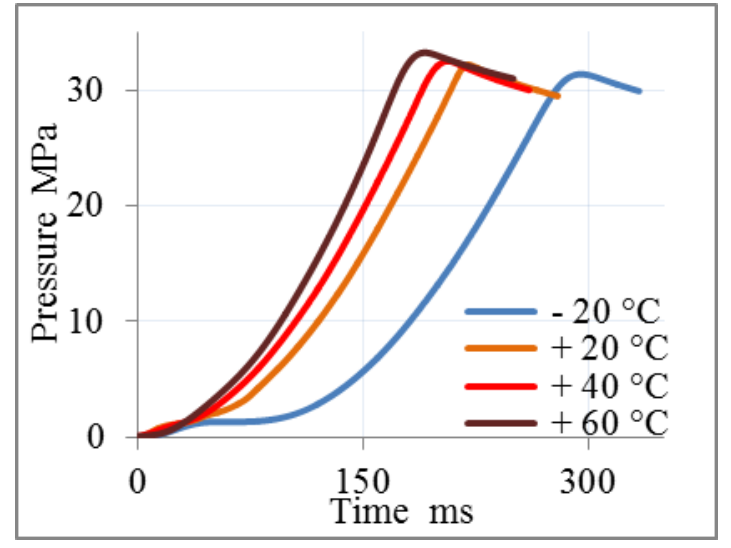

a)

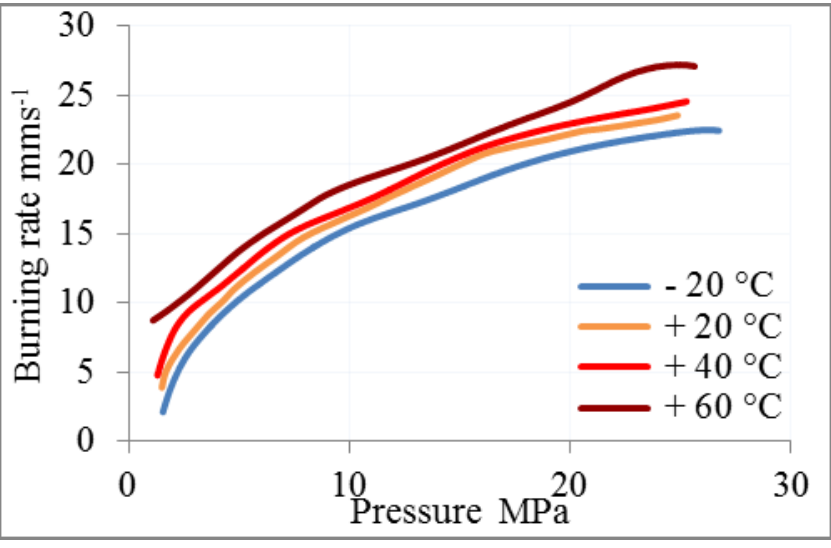

b)

Figure 7: SV-2 ballistic evaluation for ROP composition for different initial grain temperatures a) $P$ - $t$ curves

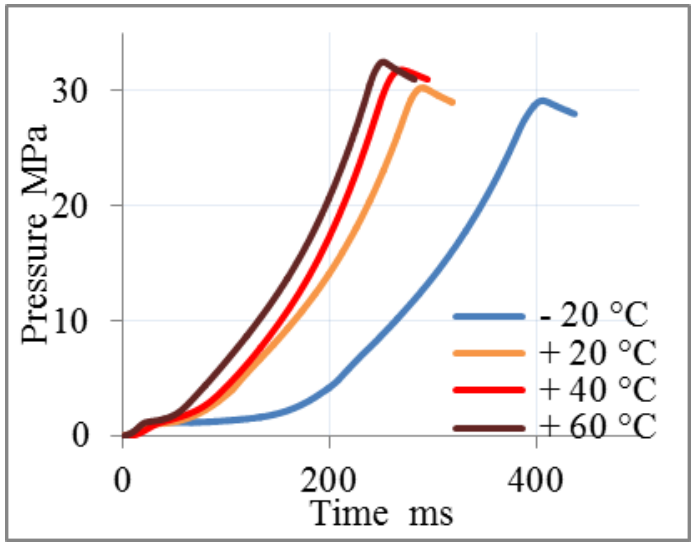

a) b) $P$ - $u$ curves

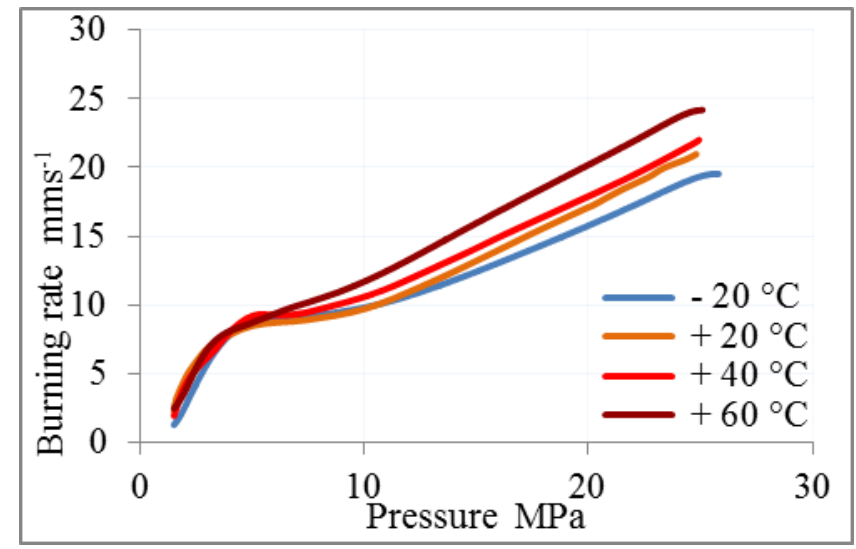

b)

Figure 8: SV-2 ballistic evaluation for GRAD composition for different initial grain temperatures a) $P$ - $t$ curves b) $P$ - $u$ curves

Table 3: Measured and calculated ballistic parameters from SV-2.

\begin{tabular}{|c|c|c|c|c|c|c|}
\hline & $\begin{array}{c}\text { Temperature } \\
{ }^{\circ} \mathrm{C}\end{array}$ & $\begin{array}{c}\text { Pressure range } \\
\mathrm{MPa}\end{array}$ & $\begin{array}{c}\text { Pressure } \\
\text { exponent } \\
n\end{array}$ & $\begin{array}{c}\text { Temperature } \\
\text { coeff. } \\
a\end{array}$ & $\begin{array}{l}\text { End burning } \\
\text { pressure } \\
\text { MPa }\end{array}$ & $\begin{array}{c}\text { Time } \\
\text { end burning } \\
\text { ms }\end{array}$ \\
\hline \multirow{4}{*}{ ROP } & -20 & \multirow{4}{*}{$2.5-25$} & 0.54 & 4.19 & 31.38 & 294.8 \\
\hline & +20 & & 0.51 & 4.76 & 32.20 & 219.8 \\
\hline & +40 & & 0.48 & 6.02 & 32.50 & 206.2 \\
\hline & +60 & & 0.43 & 6.84 & 33.25 & 190.8 \\
\hline \multirow{8}{*}{ GRAD } & \multirow{2}{*}{-20} & $3-10$ & 0.28 & 5.22 & \multirow{2}{*}{29.17} & \multirow{2}{*}{406.7} \\
\hline & & $10-25$ & 0.78 & 1.55 & & \\
\hline & \multirow{2}{*}{+20} & $3-10$ & 0.29 & 5.09 & \multirow{2}{*}{30.11} & \multirow{2}{*}{285.4} \\
\hline & & $10-25$ & 0.87 & 1.27 & & \\
\hline & \multirow{2}{*}{+40} & $3-10$ & 0.32 & 5.09 & \multirow{2}{*}{31.82} & \multirow{2}{*}{269.8} \\
\hline & & $10-25$ & 0.78 & 1.72 & & \\
\hline & \multirow{2}{*}{+60} & $3-10$ & 0.39 & 4.74 & \multirow{2}{*}{32.22} & \multirow{2}{*}{247.3} \\
\hline & & $10-25$ & 0.81 & 1.76 & & \\
\hline
\end{tabular}




\subsubsection{Subscale rocket motors}

Figures 9 and 10 show only the results obtained by shooting using one nozzle setup. It is clear that as the initial grain temperature increases, the operating pressure and the combustion end-pressure also increase while the burning duration was shortened. Figure 9 shows the $P$ - $t$ curve for the ROP propellant composition which contains carbon black as a burning rate modifier. This leads to a higher burning rate for the ROP propellant and therefore a higher operating pressure was obtained.

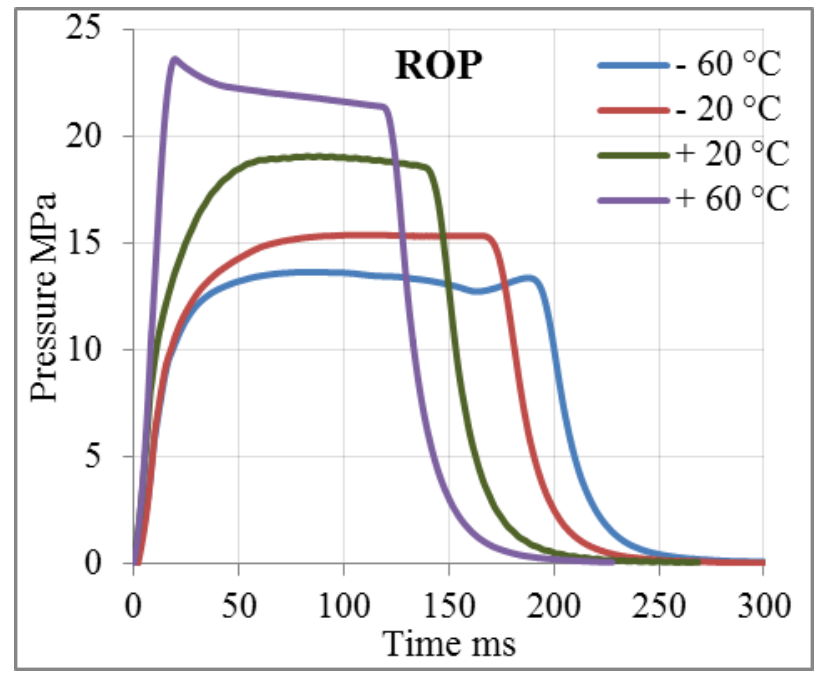

Figure 9: P-t curve for propellant ROP

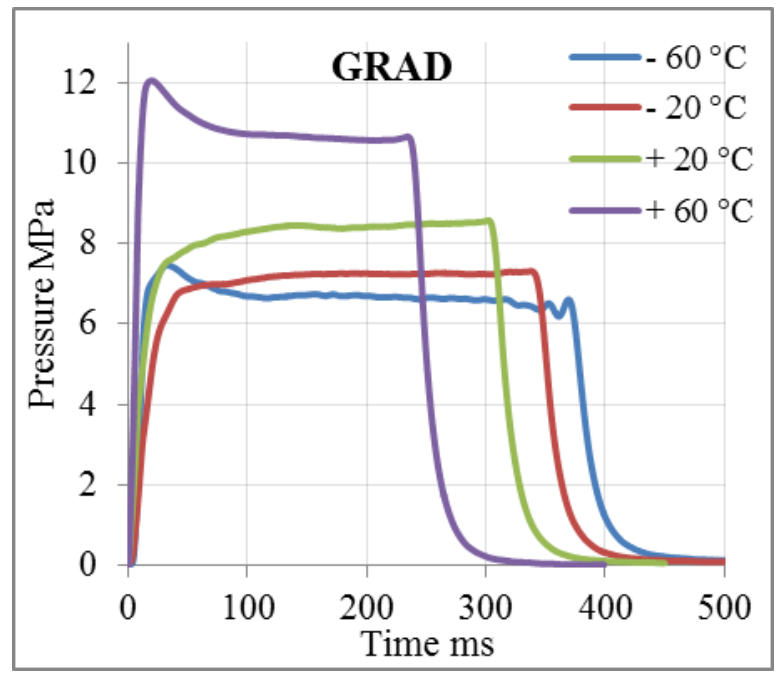

Figure 10: P-t curve for propellant GRAD

Pressure in the combustion chamber increases with increasing initial temperature of the rocket motor, and the combustion pressure achieved its operating value in a shorter time. The effective burning time, also called the action time, (the time interval between the initial and final $10 \%$ pressure points on the pressure - time dependence) was shortened with increasing initial temperature due to higher operating pressure which accelerates the burning of propellant grain.

\subsubsection{Ignition process}

Ignition delay time (IDT), also called ignition time lag, is the time from the moment the igniter receives a signal until the first surface grains start to burn. Experimentally, it is the time interval from starting the ignition to approximately $10 \%$ of the maximum pressure value. Ignition rise time (IR), also called flame spreading interval, is the time from ignition of the first grain surface until the complete grain burning surface area has been ignited. Experimentally, it is the time interval from $10 \%$ to $75 \%$ of the maximum obtained pressure. The values of time intervals for ignition delay and ignition rise for ROP and GRAD are summarized in table 4. Ignition rise time for the ROP composition was compacted to half of its value from $-60{ }^{\circ} \mathrm{C}$ to $+60{ }^{\circ} \mathrm{C}$ while GRAD composition ignition rise time was compacted to a quarter of its value for the same temperature interval. Comparison between combustion chamber pressures at ignition zones are given in table 4. Increasing of the initial grain temperature led to accelerating in the ignition process and achieving the different ignition zones with higher operating pressure within shorter time. This led to acceleration of the burning process and a shortening of the time needed for the burning process. 
Table 4: Time durations for the ignition process for ROP, GRAD 98 and GRAD 06 (IDT = ignition delay time, $\mathrm{IR}=$ ignition rise time).

\begin{tabular}{c|cc|cc|cc|cc}
\hline \multirow{2}{*}{} & \multicolumn{4}{|c|}{ ROP } & \multicolumn{4}{c}{ GRAD } \\
\cline { 2 - 10 } & \multicolumn{2}{|c|}{ IDT } & \multicolumn{2}{c|}{ IR } & \multicolumn{2}{c|}{ IDT } & \multicolumn{2}{c}{ IR } \\
\cline { 2 - 10 } & $\mathrm{t}(\mathrm{ms})$ & $\mathrm{P}(\mathrm{MPa})$ & $\mathrm{t}(\mathrm{ms})$ & $\mathrm{P}(\mathrm{MPa})$ & $\mathrm{t}(\mathrm{ms})$ & $\mathrm{P}(\mathrm{MPa})$ & $\mathrm{t}(\mathrm{ms})$ & $\mathrm{P}(\mathrm{MPa})$ \\
\hline$-60^{\circ} \mathrm{C}$ & 3.5 & 1.15 & 24.1 & 8.59 & 6.7 & 0.56 & 36 & 4.21 \\
\hline$-20{ }^{\circ} \mathrm{C}$ & 3.1 & 1.31 & 18.8 & 9.84 & 2.7 & 0.77 & 9.8 & 5.81 \\
\hline$+20{ }^{\circ} \mathrm{C}$ & 2.9 & 1.64 & 18.5 & 12.29 & 1.8 & 0.79 & 8.6 & 5.88 \\
\hline$+60^{\circ} \mathrm{C}$ & 2.4 & 1.89 & 11.9 & 14.16 & 1.1 & 0.97 & 8.5 & 7.29 \\
\hline
\end{tabular}

\subsubsection{Burning process}

The burning rate is found to be strongly affected by the operating combustion pressure which is consequentially affected by the initial temperature of the rocket motor. The dependency of the burning rate on initial temperature is presented in figure 11. The burning rate for ROP changes from $13.5 \mathrm{~mm} / \mathrm{s}$ at $-60{ }^{\circ} \mathrm{C}$ to $22.1 \mathrm{~mm} / \mathrm{s}$ at $+60{ }^{\circ} \mathrm{C}$ while GRAD changes from $8.7 \mathrm{~mm} / \mathrm{s}$ to $13.1 \mathrm{~mm} / \mathrm{s}$ for the same temperature range. The rate of increase in the burning rate for the ROP composition ( $60 \%)$ is higher than that for the GRAD composition ( $49 \%$ ) because ROP contains carbon black which may magnify the temperature effect on the burning rate.

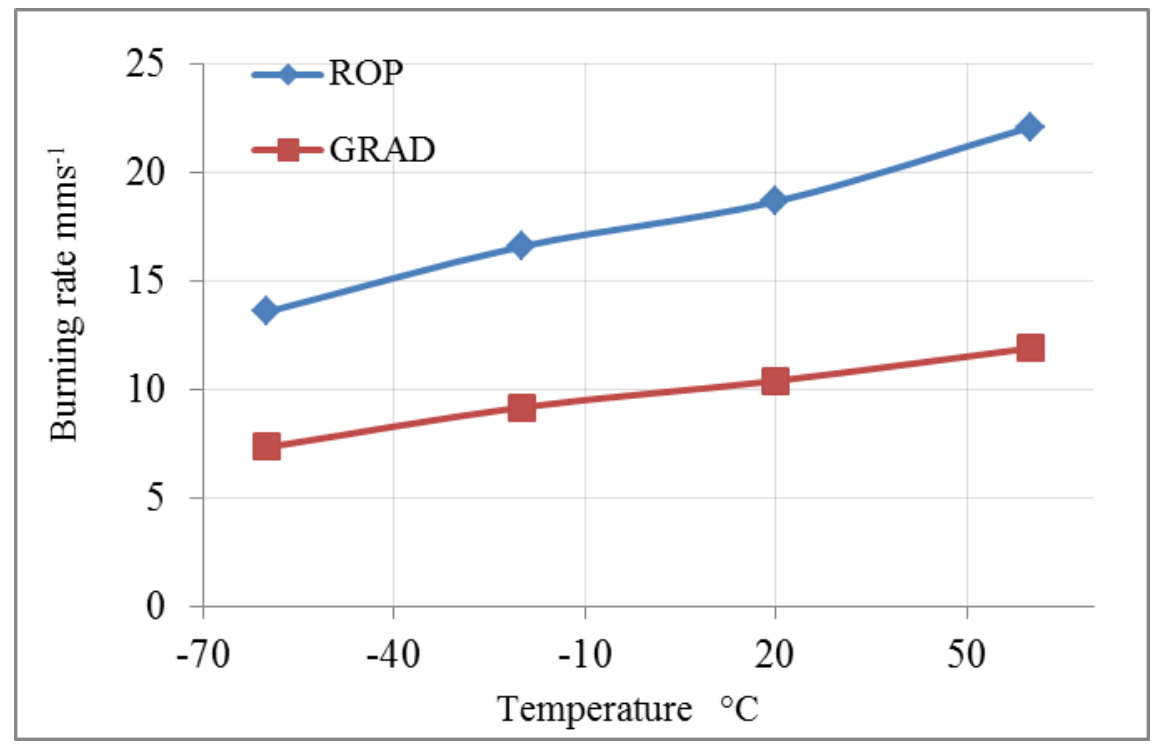

Figure 11: Effect of initial temperature on burning rate

The temperature sensitivity of burning rate, $\sigma_{p}$, expressed as the change of burning rate per degree change in propellant ambient temperature at a fixed value of operating pressure. It can be calculated from the equation:

$$
\sigma_{\mathrm{p}}=\frac{1}{r}\left(\frac{\partial r}{\partial T}\right)
$$

Where $r$ is the burning rate and $T$ is the propellant temperature. From Data given in table 5 , the temperature sensitivity of burning rate has been calculated and it was found to be 0.0021 and 0.0019 for ROP and GRAD respectively. 
Table 5: Calculated $a$ and $n$ parameters

\begin{tabular}{|c|c|c|c|c|c|c|c|}
\hline & $\begin{array}{c}\text { Temperature } \\
{ }^{\circ} \mathrm{C}\end{array}$ & $\begin{array}{l}\text { Burning Rate } \\
\mathrm{r}(\mathrm{mm} / \mathrm{s})\end{array}$ & $\begin{array}{l}\text { Operating Pressure } \\
\mathrm{P}(\mathrm{MPa})\end{array}$ & $\operatorname{Ln} r$ & Ln $\mathrm{P}$ & $\begin{array}{c}\text { Pressure } \\
\text { Exponent } \mathrm{n}\end{array}$ & $\begin{array}{l}\text { Temperature } \\
\text { Coeff. Ln a }\end{array}$ \\
\hline \multirow{20}{*}{$\begin{array}{l}0 \\
\text { ô }\end{array}$} & \multirow{5}{*}{-60} & 10.90 & 6.11 & -4.5188 & 15.624 & \multirow{5}{*}{0.44} & \multirow{5}{*}{-11.54} \\
\hline & & 12.01 & 9.99 & -4.4216 & 16.117 & & \\
\hline & & 13.66 & 10.84 & -4.2935 & 16.198 & & \\
\hline & & 15.10 & 12.89 & -4.1928 & 16.372 & & \\
\hline & & 16.20 & 15.16 & -4.1225 & 16.534 & & \\
\hline & \multirow{5}{*}{-20} & 14.80 & 9.41 & -4.2134 & 16.056 & \multirow{5}{*}{0.44} & \multirow{5}{*}{-11.40} \\
\hline & & 15.28 & 10.84 & -4.1814 & 16.199 & & \\
\hline & & 16.18 & 12.55 & -4.1240 & 16.345 & & \\
\hline & & 17.38 & 14.56 & -4.0523 & 16.493 & & \\
\hline & & 19.33 & 17.13 & -3.9458 & 16.656 & & \\
\hline & \multirow{5}{*}{+20} & 15.78 & 10.43 & -4.1487 & 16.160 & \multirow{5}{*}{0.44} & \multirow{5}{*}{-11.37} \\
\hline & & 17.28 & 12.76 & -4.0581 & 16.361 & & \\
\hline & & 18.98 & 15.20 & -3.9644 & 16.536 & & \\
\hline & & 20.39 & 17.93 & -3.8927 & 16.701 & & \\
\hline & & 20.97 & 20.09 & -3.8644 & 16.815 & & \\
\hline & \multirow{5}{*}{+60} & 19.00 & 13.63 & -3.9632 & 16.427 & \multirow{5}{*}{0.43} & \multirow{5}{*}{-11.08} \\
\hline & & 20.97 & 14.92 & -3.8648 & 16.517 & & \\
\hline & & 22.36 & 18.03 & -3.8005 & 16.707 & & \\
\hline & & 23.79 & 21.17 & -3.7385 & 16.868 & & \\
\hline & & 24.47 & 23.43 & -3.7102 & 16.969 & & \\
\hline \multirow{24}{*}{ 悹 } & \multirow{5}{*}{-60} & 5.08 & 3.06 & -5.2834 & 14.933 & \multirow{5}{*}{0.72} & \multirow{5}{*}{-16.15} \\
\hline & & 6.37 & 4.93 & -5.0558 & 15.410 & & \\
\hline & & 6.92 & 5.65 & -4.9739 & 15.546 & & \\
\hline & & 8.59 & 6.62 & -4.7567 & 15.705 & & \\
\hline & & 9.69 & 7.17 & -4.6364 & 15.785 & & \\
\hline & \multirow{5}{*}{-20} & 6.98 & 4.41 & -4.9648 & 15.299 & \multirow{5}{*}{0.69} & \multirow{5}{*}{-15.54} \\
\hline & & 8.70 & 5.44 & -4.7446 & 15.509 & & \\
\hline & & 9.30 & 6.49 & -4.6776 & 15.685 & & \\
\hline & & 10.28 & 7.04 & -4.5773 & 15.766 & & \\
\hline & & 10.59 & 8.06 & -4.5477 & 15.902 & & \\
\hline & \multirow{5}{*}{+20} & 8.45 & 5.42 & -4.7732 & 15.504 & \multirow{5}{*}{0.68} & \multirow{5}{*}{-15.32} \\
\hline & & 9.24 & 6.11 & -4.6844 & 15.625 & & \\
\hline & & 10.93 & 7.17 & -4.5166 & 15.785 & & \\
\hline & & 11.25 & 8.21 & -4.4869 & 15.920 & & \\
\hline & & 12.12 & 9.20 & -4.4130 & 16.034 & & \\
\hline & & 9.01 & 6.03 & -4.7099 & 15.611 & & \\
\hline & & 10.45 & 6.87 & -4.5610 & 15.743 & & \\
\hline & & 11.72 & 8.27 & -4.4464 & 15.928 & & \\
\hline & & 13.39 & 10.67 & -4.3134 & 16.182 & & \\
\hline & +60 & 14.98 & 12.24 & -4.2008 & 16.320 & 0.67 & -15.18 \\
\hline & & 11.81 & 7.93 & -4.4384 & 15.885 & & \\
\hline & & 12.90 & 9.43 & -4.3504 & 16.059 & & \\
\hline & & 13.90 & 10.64 & -4.2758 & 16.179 & & \\
\hline & & 16.15 & 14.35 & -4.1261 & 16.479 & & \\
\hline
\end{tabular}

\section{Conclusion}

Measurements of the solid propellant burning rate can be conducted with several methods. According to the measuring conditions and the required data, the most proper method should be selected for the burning rate measurements. Regarding the present work, the subscale rocket motors can be considered the closest method to simulate the reality in spite it requires more money, efforts, and time consuming. Modified SV-2 for the strand burning provides burning rate measurements close to the results obtained by the popular subscale motors method. The sample preparation for firing in both subscale motors or in strand burning has its details but the sample preparation for strand burning is easier requires fewer details and fewer supporting parts. One confirmed firing from either subscale motor or 
strand burning results in only one point on the desired $P-u$ curve. Due to the time consumed in sample installment to the strand burning instrument (about 2 - 3 minutes), the strand burning can be considered a not suitable technique for studying the effect of initial grain temperature on the burning rate. Another reason is the effect of nitrogen gas, the nitrogen gas comes from high pressure storage bomb becomes cold when it passed through a valve to the relatively lower pressure measuring bomb which affects the sample temperature. Strand burning measurements are favorable to measure the burning rates at lower operating pressures due to combustion instabilities arises inside the subscale motors which affects the burning process and measured data.

SV-2 closed vessel can be considered a more convenient method to measure the burning rate from economical point of view. It requires fewer samples and lowers efforts to estimate the burning rate along a wide operating pressure range. The firing of one sample confirmed by a second shot is sufficient to plot a trusted P-u curve. The preparation of the sample for firing in SV-2 is easier than preparing the subscale rocket motor for firing due to the details of the sample fixation in the rocket motor and many small parts included in the subscale rocket motor. Both subscale rocket motors and the closed vessel SV-2 are convenient to measure the burning rate and to study the effect of initial grain temperature on the burning process while for studying the effect of initial temperature on the ignition process, the subscale motors are more favorable due to detailed information for the different ignition zones.

\section{References}

[1] Agrawal JP. (2010) High energy materials. Weinheim: EY-VCH Verlag GmbH \& Co. KGaA; pp. 320-324.

[2] Alain Davenas, (1993) Solid Rocket Propulsion Technology, Pergamon Press, First English edition, pp. 111-190.

[3] Atwood A. I., Boggs T. L., Curran P. O., Parr T. P., Hanson-Parr D. M., Price C. F., Wiknich J., (1999) Burning rate of solid propellant ingredients, part 1: pressure and initial temperature effects, Journal of Propulsion and Power, 15(6), pp. 740-747.

[4] Blair, David W., (1970) Initial temperature and pressure effects on composite solidpropellant burning rates: comparisons with theory, AIAA Journal, 8(8), pp.1439-1443.

[5] Collins H. L., (1947) Experimental study of the burning rate of some solid propellants by using a closed bomb, Thesis, California Institute of Technology.

[6] Crawford B.L., Hugget C., Daniels F., Wilfong R.E., (1947) Direct determination of burning rates of propellant powders, Analytical Chemistry, 19(19), pp. 630-633.

[7] Degirmenci E., (2015) Effects of grain size and temperature of double base solid propellants on internal ballistics performance, Fuel, 146, pp. 95-102.

[8] DeLuca L.T., Maggi F., Annovazzi A., Hessler R.O., Glick R.L., ( 2002) Burning rate measurements from small-scale test motors, RTO AVT Specialists, Meeting on Advances in Rocket Performance Life and Disposal, Aalborg, Denmark.

[9] Ewing, D. L., Osborn, J. R, (1971) Burning rate temperature sensitivity of composite solid propellants, Journal of Spacecraft and Rockets, 8(3), pp. 290-292. 
[10] Fry R.S., (1995) Review of burning rate measurement methods in the US, briefing to the NATO RTO/AVT WG 016 (formerly AGARD/PEP WG 27).

[11] Fry R.S., (1998) Solid rocket motor test and test techniques, component testing \& verification, solid propellant burning rate, AIAA Solid Rocket Technical Committee Lecture Series, $36^{\text {th }}$ Aerospace Sciences Meeting.

[12] Fry R. S., (2001a) Evaluation of methods for solid propellant burning rate measurements, NATO RTO Advisory Report, NATO RTO AVT Working Group 016, Chaired \& Edited by, Johns Hopkins University-CPIA.

[13] Fry R.S, (2001b) Solid propellant subscale burning rate analysis methods for US and selected NATO facilities, JHU/CPIA, CPTR-75.

[14] Fry R.S., (2001c) Solid propellant subscale burning rate test techniques and hardware for US and selected NATO facilities, JHU/CPIA, CPTR-74.

[15] Fry R.S., (2001d) Solid propellant test motor scaling for US and selected NATO facilities, JHU/CPIA, CPTR-73.

[16] Garima G., Lalita J., Mehilal, Bikash B.,(2015) Various methods for the determination of the burning rates of solid propellants - An Overview, Central European Journal of Energetic Materials, 12(3), pp. 593-620.

[17] Glick, Robert L., (1967) Temperature sensitivity of solid propellant burning rate, AIAA journal, 5(3), pp. 586-587.

[18] Grune D., Kegler W., Nicolas M., Benhaim P., (1977) Studies of the combustion of solid propellants at high pressures, Proc. Int. Symp. Ballist., $3^{\text {rd }}$, A2.

[19] Hermance E., (1961) Comparison of solid propellant burning rates In strands and rocket motors, Department of Aeronautical Engineering, Princeton University, Princeton, New Jersey.

[20] Hessler R.O., Glick R.L., (1997) Comments on burning rate measurement in rocket motors, Memorandum to RTO/AVT WG016.

[21] Hessler R.O., Glick R.L., (1999) Error analysis of burning rate measurement procedures, Workshop on Errors and Noise in Energetic Material Combustion Experiments, Politecnico di Milano, Milan, Italy.

[22] Jolley H., (1977) Timing instrumentation for A crawford type strand burner, Defence Science and Technology Organisation, Australia.

[23] Kirk W., (1977) Description of the W.R.E. strand burning facilities and instructions for use weapon research Establishment W R E Adelaide Australia.

[24] Kosanke K.L., Kosanke B.J., Sturman B., Shimizu T., Wilson M., (2004) Pyrotechnic chemistry. Pyrotechnic reference series, No: 4, Journal of Pyrotechnics, USA, Chapter 8, pp. 1-8. Chapter 11, pp. 1-22. Chapter 12, p. 1-23, ISBN: 1-889526-15-0.

[25] Kubota N., (2002) Propellants and Explosives: Thermochemical Aspects of Combustion, Wiley-VCH Publication, Germany, ISBN 978-3-527-33178-9.

[26] Nelson B., (1977) Burning rates of standard army propellants in strand burner and closed chamber tests U.S.A Army Ballistic Research Laboratory Aberdeen Proving Ground Maryland.

[27] Phung P.V., Hardt A.P., (1968) Burning rates of solid propellants by a variable pressure method, Explosivstoffe,16(12), pp. 274-280. 
[28] Pietrobon A., (2003) Improved strand burn rate reproducibility using a new preparation methodology for paint-based inhibitors, Australian Goverment Department of Defence.

[29] Rodolphe S., Jason P. ,Eric P., (2005) High pressure testing of composite solid propellant mixtures: burner facility characterization 41st AIAA/ASME/SAE/ASEE Joint Propulsion Conf. \& Exhibit Tucson Arizona.

[30] Shekhar, Himanshu, (2009) Estimation of pressure index and temperature sensitivity coefficient of solid rocket propellants by static evaluation, Defence Science Journal, 59(6), pp. 666-669.

[31] Ulas A., Risha G.A., Kuo K.K.,(2006) Ballistic properties and burning behavior of an ammonium perchlorate/guanidine nitrate/sodium nitrate airbag solid propellant, Fuel,85, pp. 1979-1986.

[32] Wu Xiong-G., Yan L., Guo X., Qi X., Li X., Wang K., (2011) Combustion efficiency and pyrochemical properties of micron-sized metal particles as the components of modified double-base propellant, Acta Astronaut, 68, p 1098-1112,.

[33] Yaman H., V. Celik, E. Degirmenci, (2014) Experimental investigation of the factors affecting the burning rate of solid rocket propellants, Fuel,115, pp. 794-803.

[34] Yilmaz N., Donaldson B., Gill W., (2008) Solid propellant burning rate from strand burner pressure measurement, Propellants, Explosives, Pyrotechnics,33(2), pp. 109-117.

[35] Young G.H.S., (1960) Methods of burning rate control in solid propellants, AGARD Combustion and Propulsion Panel. Pergamon Press, pp. 285-302.

[36] Yilmaz N., Donaldson B., Gill W., (2008) Solid propellant burning rate from strand burner pressure measurement, Propellants, Explosives, Pyrotechnics, 33(2), pp. 109-117. 